\title{
Resenha \\ Saúde Mental: Múltiplos Saberes, Diversas Considerações
}

\author{
Marcelo Simões Mendes ${ }^{1}$ \\ Universidade Estadual de Campinas

\section{Book Review Mental Health: Multiple Knowledge, Various Considerations}

O médico Paulo Amarante (2013) apresenta na quarta edição de sua obra Saúde Mental e Atenção Psicossocial interessantes e importantes questões que envolvem o campo da Saúde Mental. Seus apontamentos não apenas se referem a como se deu a construção dessa área ao longo do tempo, mas a como toda a conjuntura estrutural desse campo se reflete na maneira como a Saúde Mental é concebida, interpretada e 'utilizada' nos tempos contemporâneos.

Como ponto de partida, Amarante (2013) discute os aspectos a serem levados em consideração para caracterizar e assim delimitar o complexo e ramificado campo da Saúde Mental. Diferentemente de outras áreas do saber que possuem um objeto mais específico e direcionado, a área da Saúde Mental se apresenta atualmente como uma construção conjunta entre diversas áreas do saber que não somente a psiquiatria e a neurologia. Nas palavras do autor, "Saúde Mental não é apenas psicopatologia, semiologia... Ou seja, não pode ser reduzida ao estudo e tratamento das doenças mentais" (Amarante, 2013, p. 16). A título de exemplificação, o trabalho prático em Saúde Mental já não envolve apenas psiquiatras, psicólogos e neurologistas, conta com a contribuição de diversos outros profissionais, como o enfermeiro, o assistente social, o educador físico, o pedagogo, entre outros.

Diante de toda essa pluralidade de conhecimentos, de formações e de profissionais que atuam nesse campo, torna-se relevante apontar uma ambiguidade. Embora a Saúde Mental agregue em seu escopo uma diversificada gama de áreas do conhecimento - como fisiologia, a filosofia, a antropologia -, do ponto de vista conceitual, esse campo denota a dificuldade e o enorme desafio de ser concebido segundo uma única perspectiva. Essa dificuldade pode também ser facilmente identificada no campo aplicado, uma vez em que, atravessando a 'era da multi, inter e transdisciplinaridade', o trabalho que envolve diversas formações e profissionais tem mostrado suas dificuldades de concretização.

Amarante (2013) apresenta, ainda, o percurso histórico sobre como a Saúde Mental, ou melhor, a doença mental foi tratada e institucionalizada ao longo dos tempos. Para tanto, torna-se imprescindível destacar uma instituição ímpar nesse processo: o hospital. Conforme aponta o autor, na Idade Média, o hospital cumpria a função de oferecer abrigo, alimentação e assistência religiosa aos pobres, mendigos e doentes. Torna-se relevante assinalar que, nesse momento, a loucura já recebia diversas denominações: "de demônios a endeusados, de comédia e tragédia, de erro e verdade"

1 Endereço para correspondência: Faculdade de Ciências Médicas, Rua Tessália Vieira de Camargo, 126, Cidade Universitária Zeferino Vaz, Campinas, SP, Brasil. CEP 13083-887.E-mail: m_smendes@yahoo. com.br
(Amarante, 2013, p. 23). Com o passar do tempo e com a criação do Hospital Geral em 1656 na França, a instituição hospitalar já começara a apresentar uma ordem social e política mais clara e definida. Após a Revolução Francesa, o hospital se assume como uma instituição mais próxima do que conhecemos. O então hospital fora medicalizado e com isso a atuação médica torna-se cada vez mais marcante.

Philippe Pinel, conhecido como o pai da Psiquiatria, passou a dirigir uma das unidades do Hospital Geral e, em sua concepção, os 'loucos' "devem ser submetidos a um tratamento asilar, sob um regime de completo "isolamento" (Amarante, 2013, p. 29). Aproveitando as considerações de Amarante (2013) quando aponta que os pressupostos delegados a esse tipo de tratamento realizado em 1793 ainda não foram superados atualmente, torna-se cabível aproveitar o ensejo dessa discussão para algumas considerações mais. Uma importante contribuição desta obra consiste na reflexão sobre como a loucura foi concebida e tratada ao longo dos tempos. Ainda que alguns argumentos de Pinel pudessem carregar ideários de liberdade - próprios da Revolução Francesa -, o método de isolamento para tratamento do paciente 'louco' traz consigo algumas características socioculturais sobre como a loucura - ou a alienação - era concebida. Tal concepção parece não estar tão distante do que podemos observar nos tempos atuais.

E possível identificar avanços no campo do tratamento em Saúde Mental no Brasil. A luta antimanicomial e o processo de desinstitucionalização da doença e/ou do doente mental avançou, seja no campo das políticas públicas ou dos tratamentos especializados. No entanto, podem-se observar inúmeras barreiras no que se refere à continuidade desses avanços no campo da Saúde Mental. Parte das barreiras enfrentadas envolve a diversidade de áreas do saber e de profissionais que compõem o campo. Sem uma discussão múltipla que leve em consideração tal diversidade, o campo aplicado do trabalho em Saúde Mental, mediado pelos vários profissionais que o compõem, parece não apenas desconhecer as possibilidades de sua atuação como também ter dificuldade de compreendê-la. A atuação em Saúde Mental não se reduz a determinadas especialidades com alguns conhecimentos a respeito do adoecimento mental. Pensar na atuação em Saúde Mental pode significar repensar a concepção da construção dessa área.

Atento a essas considerações, mas procurando avançar na análise da obra de Amarante (2013), deve-se assinalar que o cenário da segunda guerra possibilitou o desenvolvimento de algumas formas de conceber e tratar os transtornos mentais. O pós-guerra se deparava com uma difícil condição: jovens sobreviventes precisavam passar de soldados a trabalhadores, ainda que suas condições físicas e psicoafetivas pudessem 
estar profundamente abaladas. Em meio a esse cenário, Main e Bion Reichman de Birmingham, na Inglaterra, propuseram um modelo extremamente revolucionário e importante na área do tratamento em Saúde Mental, tão importante que podemos observar os princípios dessa iniciativa em diversas instituições de tratamento em Saúde Mental no Brasil e no mundo atualmente. Trata-se de considerar e fazer uso do potencial dos próprios pacientes no processo de reabilitação e tratamento. Exemplificando o modelo de Birmingham: "Organizavam reuniões em que discutiam as dificuldades, os projetos, os planos de cada um; realizam assembleias com duzentos ou mais pacientes; elaboravam propostas de trabalho em que todos (pacientes e funcionários) pudessem estar envolvidos etc." (Amarante, 2013, p.42).

Historicamente, o caminho percorrido pela Psicologia trouxe - ou ainda traz - o sujeito com algum tipo de 'doença mental' em sua condição passiva diante das dificuldades com que pudesse se deparar. Especialmente na segunda metade do século passado e no início do corrente, algumas áreas da Psicologia, como a Psicologia Social (Lane \& Codo, 2006) e mais recentemente a Psicologia Positiva (Seligman \& Csikszentmihalyi, 2000), procuram lançar um olhar para o sujeito não mais acometido e vitimizado pelo seu diagnóstico, mas como um ser dotado de potencialidades e, assim, responsável pela a autoria de sua história. Uma importante consideração é que este olhar não pormenoriza a gravidade das situações e condições do sujeito mas sim as coloca sob outro enfoque, outra perspectiva.

A perspectiva de trabalho desenvolvida em Birmingham parece confluir com essa maneira de compreender e conceber o 'doente mental' apontada no parágrafo anterior. Sob essa ótica, o fortalecimento psicossocial já não se apresenta como exterior ao sujeito em um movimento unilateral - de fora para dentro. Colocando o sujeito em uma posição de importante relevância - e por que não a mais importante? em seu processo de tratamento, o fortalecimento psicossocial no campo da Saúde passa a ser compreendido não apenas de uma maneira bidirecional, mas multidirecional, pois, a partir do momento em que o sujeito passa a ocupar um importante papel em seu processo de tratamento, a percepção e a concepção dessas redes de atenção psicossocial tendem a ser revistas e ampliadas.

Dessa maneira, a atenção e o fortalecimento psicossocial passam a ocupar o conjunto final da obra de Paulo Amarante (2013). Esses assuntos são discutidos inclusive no campo das políticas públicas. É importante apontar o quão relevante as discussões provenientes da área das Ciências Sociais e Humanas em Saúde podem se apresentar na construção das políticas em Saúde Mental, uma vez que o direcionamento dessas discussões possui uma estreita convergência para o delineamento dessas políticas. Em outras palavras, as políticas públicas precisam se ocupar, cada vez mais, das discussões sobre autonomia e agência na área da Saúde Mental de forma plural, uma vez que o fortalecimento psicossocial implica e é implicado por esses aspectos.

Em suma, de uma maneira inclusive didática e com uma linguagem de bom acesso, a obra de Paulo Amarante (2013) possibilita ao leitor uma compreensão ampliada acerca das discussões que envolvem o campo da Saúde Mental atualmente. Essa compreensão não se dá somente mediante o ramo de assuntos, aspectos e fatores contemporâneos apontados, mas por permitir uma compreensão contextualizada sobre como a área da Saúde Mental foi construída ao longo da história. Trata-se de uma leitura imprescindível para quem aspira conhecer, atuar e discutir a Saúde Mental com seus parâmetros básicos de solidez.

\section{Referências}

Amarante, P. (2013). Saúde Mental e Atenção Psicossocial. (4ª ed.). Rio de Janeiro: Fiocruz.

Lane, S. T. M., \& Codo, W. (2006). Psicologia Social: o homem em movimento (13 $3^{\mathrm{a}}$ ed.). São Paulo: Brasiliense.

Seligman, M. E. P., \& Csikszentmihalyi, M. (2000). Positive Psychology: An Introduction. American Psychologist, 55(1), 5-14.
Recebido em 26.02.2014

Primeira decisão editorial em 23.01.2015

Aceito em 23.01.2015 